http://jmscr.igmpublication.org/home/ ISSN (e)-2347-176x ISSN (p) 2455-0450

crossref DOI: https://dx.doi.org/10.18535/jmscr/v7i12.75

Journal Of Medical Science And Clinical Research

\title{
An audit of microvascular free tissue transfers for post-traumatic lower limb defects
}

\author{
Authors \\ Dr Aditya Vora ${ }^{1}$, Dr Amarnath Munoli ${ }^{2 *}$ \\ ${ }^{1}$ Superspeciality Medical Officer, Department of Plastic and Reconstructive Surgery LTMGH, Sion, \\ Mumbai \\ ${ }^{2}$ Associate Professor, Department of Plastic and Reconstructive Surgery LTMGH, Sion, Mumbai \\ Corresponding Author \\ Dr Amarnath Munoli
}

$4^{\text {th }}$ Floor Room Number 450 College Building Department of Plastic Surgery Sion Hospital Mumbai 400022

\begin{abstract}
Background: Lower limb defects following compound fractures are a major cause of morbidity following trauma. Local reconstructive options are often limited necessitating microvascular free flap reconstruction.

Materials and Methods: A retrospective evaluation of all patients undergoing microvascular free flap reconstruction for post-traumatic lower limb defects from January 2011 to December 2014 at a tertiary health care centre was performed. All patients were evaluated for etiology, site of the defect, free flap used, recipient vessel, type of anastomosis, flap survival and post-operative complications.

Results: Of all the 22 patients evaluated with a mean age of 27.7 years (range 8-66 years), 18 were males and 4 females. Road traffic accident was the major mode of trauma (18 patients) followed by railway accident (2), fall from height (1), assault (1). Flaps used were ALT flaps (14), Latissimus Dorsi (6), gracilis (2). Most common site of defect was lower third leg (15) followed by middle third leg (2), foot and sole (5). Fasciocutaneous flaps were done in 14 patients and muscle flaps were done in 8 patients. The overall survival rate was $90.90 \%$ (20/22) with partial necrosis in 2 patients. End to end anastomosis was done in 18 patients and end to side anastomosis was done in 4 patients.

Conclusions: Microvascular free flaps are an integral part of treatment for post-traumatic lower limb defects. Excellent outcomes can be achieved by thorough debridement, appropriate recipient vessel and flap selection and careful post-operative management.

Keywords: Lower limb defects, free flap, muscle flaps, fasciocutaneous flaps.
\end{abstract}

\section{Introduction}

Lower extremity injuries represent the primary cause of more than half of all hospitalizations for trauma ${ }^{1}$. They usually involve young patients in the age group of $20-30$ years $^{2}$. The advent of reconstructive microsurgery has led to a new phase of possibilities for salvage following major limb trauma. Although pedicled fasciocutaneous or muscle flaps continue to be useful options, microsurgical free flaps are usually necessary for larger defects and for areas where there are no locoregional options. 


\section{Aims and Objectives}

- To evaluate the survival rate of microvascular free flaps used in posttraumatic lower limb defects.

- To study various parameters of microvascular reconstruction of post traumatic lower limb defects.

\section{Materials and Methods}

This is a retrospective study of 22 patients who underwent microvascular free flap reconstruction for post-traumatic defects of the lower limb at a tertiary health centre in Mumbai. All patients were initially admitted in orthopedic department for primary bone stabilization with external fixation devices and were then referred to the Plastic Surgery unit for management of open wounds. All patients with lower limb defects were examined with reference to nature of the defect (duration, site, size, soft tissue/ bony/complex defect), pulsations, general condition and fitness for major surgery. For those with absent lower limb pulsations- Color Doppler /angiographic evaluation were done. All patients underwent one surgical setting of debridement prior to definitive flap cover surgery. Surgery was performed with a two-team approach i.e. one team harvesting the flap and the other team performing dissection of recipient vessels beyond the zone of trauma and preparing the defect for receiving the flap. The recipient vessels (Anterior or posterior tibial artery) were selected based on findings of preoperative clinical examination, Doppler/ angiography findings and location of defect. The flap was tailored to fit the defect after debridement and excision of fibrosed margins. Following flap harvest, the donor vessels were divided, the flaps were transferred to the recipient site, sutured in place after appropriate positioning of the vessels and vascular repair was performed. End-to-end anastomosis of donor \& recipient arteries and veins was done in most cases. End to side arterial repair was performed in 4 patients with significant size discrepancy. Post operatively all patients were given splintage and leg elevation. Postoperative LMW Heparin (once daily) was administered to all patients. Patients were adequately hydrated to maintain a Urine output of $1.5-2 \mathrm{ml} / \mathrm{kg} / \mathrm{hour}$ and the flaps were monitored closely for signs of vascular compromise and need for re-exploration--hourly for 24 hours, two hourly for the next 48 hours and 4 hourly till day 5. All patients were followed up for at least 6 months.

\section{Observation}

Table 1- Sex distribution

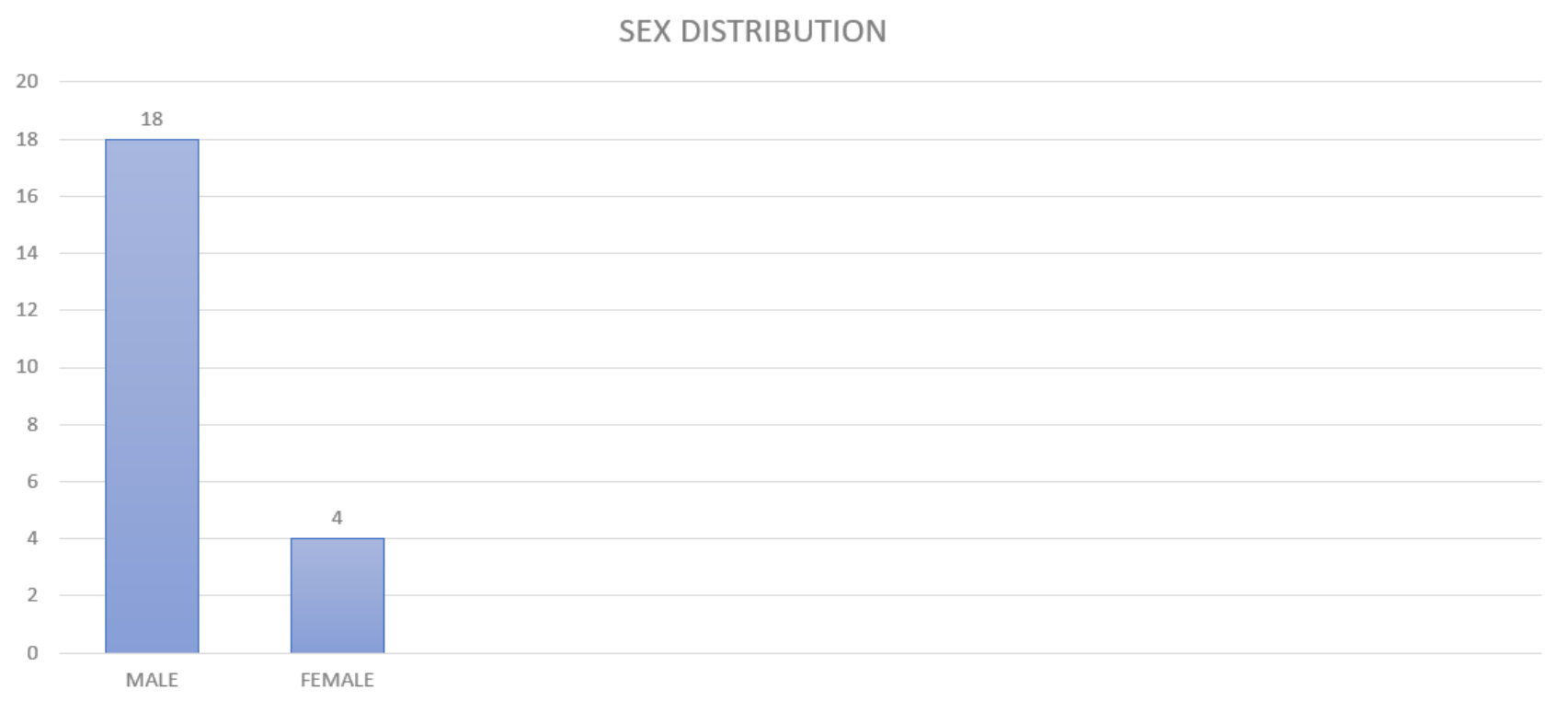




\section{JMSCR Vol||07||Issue||12||Page 414-419||December}

Table 2- Distribution of defects in the leg

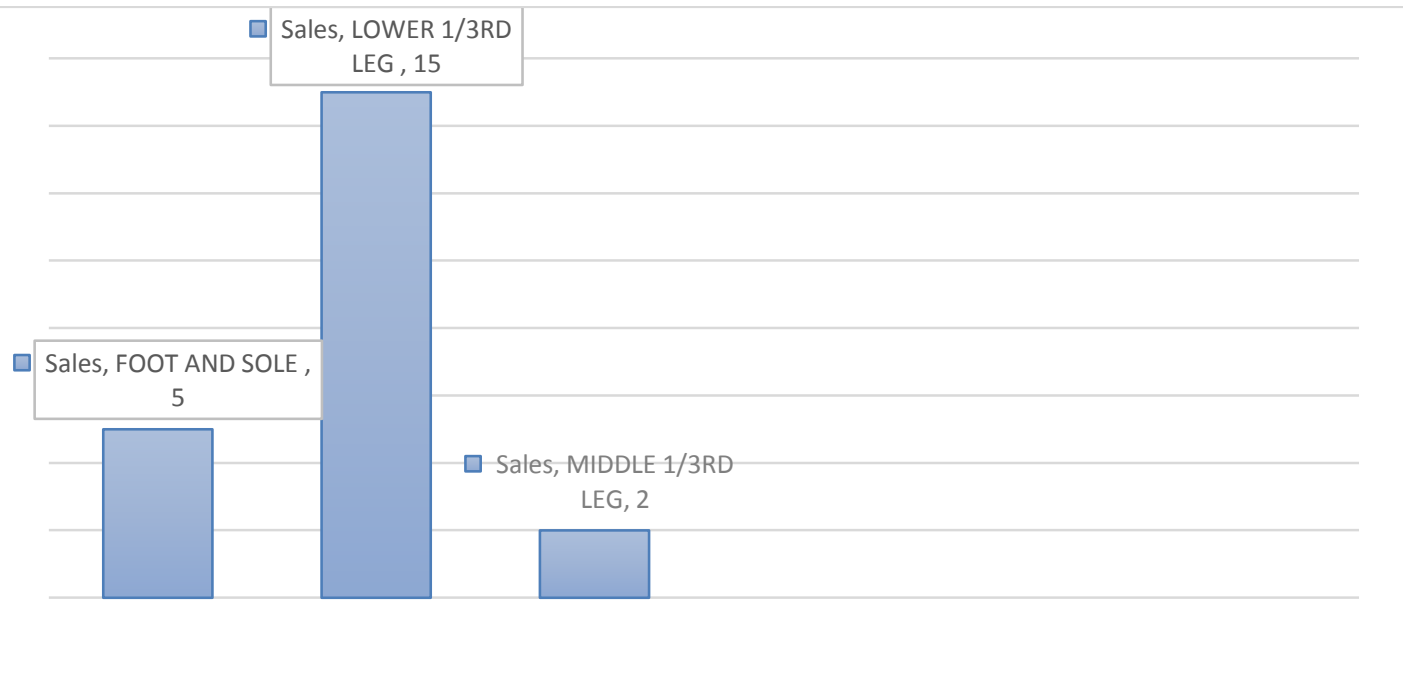

Table 3 - Modes of injury

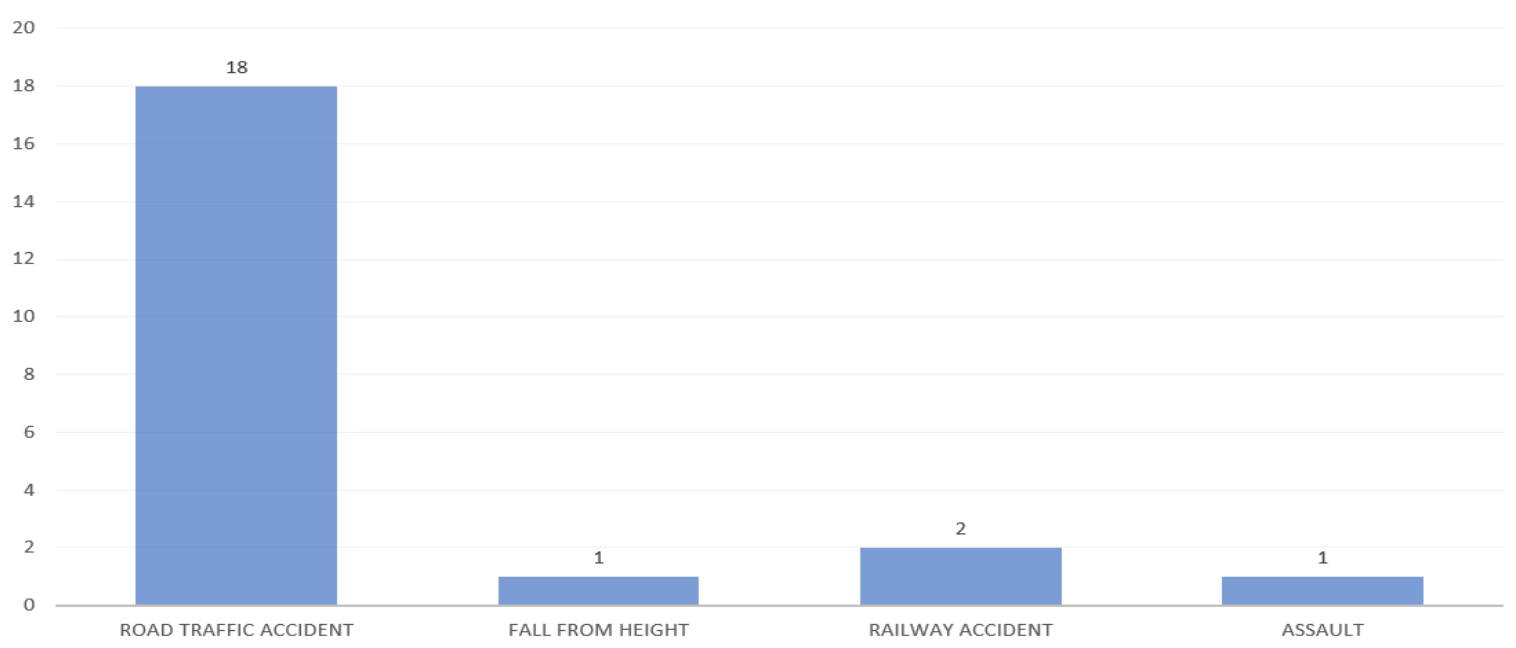

Table 4 - Different flaps done for the leg defects

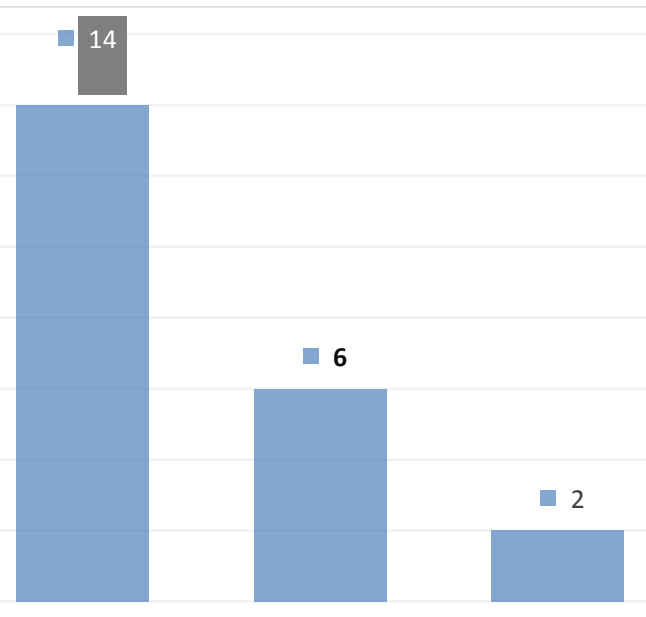


Table 5 Results of survival of individual flaps

\begin{tabular}{|l|l|l|l|l|}
\hline & TOTAL NUMBER & PARTIAL NECROSIS & $\begin{array}{l}\text { COMPLETE } \\
\text { NECROSIS }\end{array}$ & SURVIVAL RATE \\
\hline $\begin{array}{l}\text { ANTEROLATERAL } \\
\text { THIGH FLAP }\end{array}$ & 14 & 1 & 1 & $92.85 \%$ \\
\hline $\begin{array}{l}\text { LATISSIMUS DORSI } \\
\text { FLAP }\end{array}$ & 6 & 1 & 1 & $83.33 \%$ \\
\hline GRACILIS FLAP & 2 & 0 & 0 & $100 \%$ \\
\hline
\end{tabular}

Table 6 Survival rates of fasciocutaneous and muscle flaps

\begin{tabular}{|cccc|}
\hline TYPE OF FLAPS & TOTAL NUMBER & COMPLETE NECROSIS & SURVIVAL RATE \\
\hline FASCIOCUTANEOUS FLAPS & 14 & 1 & $92.85 \%$ \\
\hline MUSCLE FLAPS & 8 & 1 & $87.50 \%$ \\
\hline
\end{tabular}

Table 7 Survival rate of flaps with end to end and end to side anastomosis

\begin{tabular}{|cccc|}
\hline ANASTOMOSIS & TOTAL NUMBER & $\begin{array}{c}\text { COMPLETE } \\
\text { NECROSIS }\end{array}$ & SURVIVAL RATE \\
\hline END TO END ANASTOMOSIS & 18 & 2 & $88.88 \%$ \\
\hline END TO SIDE ANASTOMOSIS & 4 & 0 & $100 \%$ \\
\hline
\end{tabular}
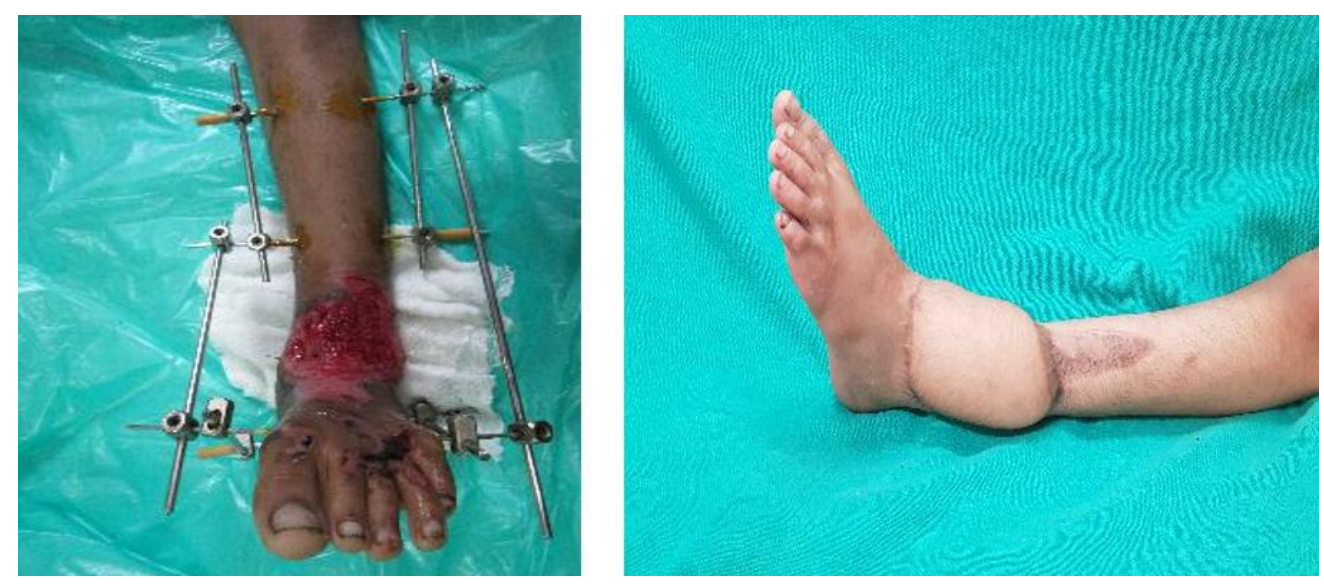

Figure 1- Free ALT flap done for lower 1/3 leg and ankle defect
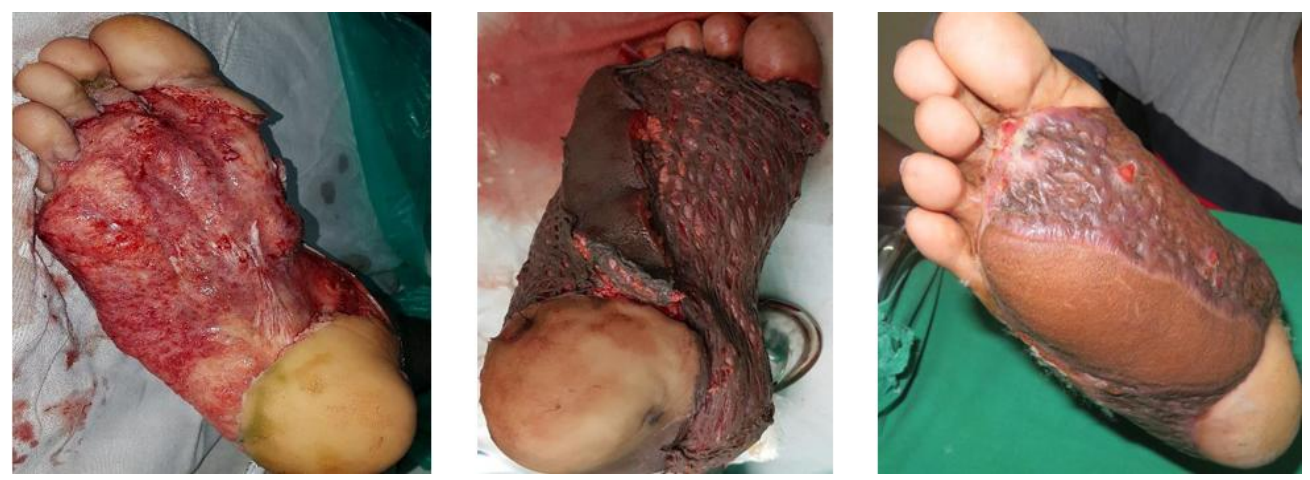

Figure 2 - Free latissimus dorsi flap done for sole defect 

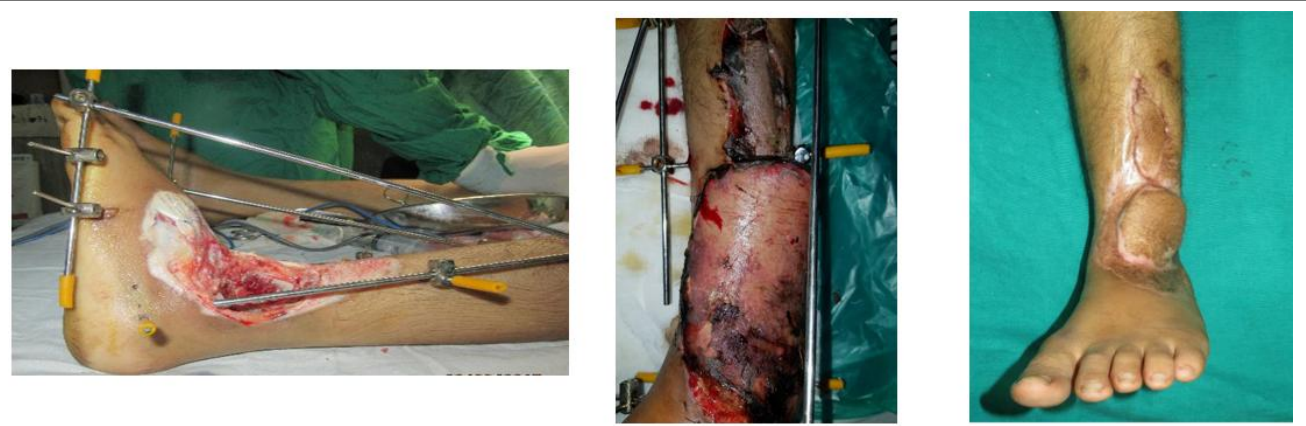

Figure 3 - ALT flap done for lower third leg and ankle defect which developed partial necrosis. The necrosed flap was debrided and STSG done.

\section{Results}

Of all the 22 patients evaluated with a mean age of 27.7 years (range 8-66 years), 18 were males and 4 females. Road traffic accident was the major mode of trauma (18 patients) followed by railway accident (2), fall from height (1), assault (1). Flaps used were ALT flaps (14), Latissimus Dorsi (6), gracilis (2). Most common site of defect was lower third leg (15) followed by middle third leg (2), foot and sole (5). Fasciocutaneous flaps were done in 14 patients and muscle flaps were done in 8 patients. The overall survival rate was $90.90 \%$ (20/22) which is comparable to other reported series of lower limb reconstruction ${ }^{3}$. Of the 22 flaps, 2 had complete necrosis and needed a second flap for cover of exposed vital structuresboth underwent cross leg flap cover. 2 patients had partial necrosis of the free flap--1 required debridement and secondary suturing while another required debridement and skin grafting. Of the 14 fasciocutaneous flaps done 1 had complete necrosis and out of 8 muscle flaps 1 had complete necrosis. Of the 18 end to end anastomosis there was complete necrosis in 2 patients and all 4 cases of end to side anastomosis survived. However, this difference is not significant due to the small number of end-to-side anastomosis. In either case there is no statistical difference in survival rates between fasciocutaneous and muscle flaps and between end to end and end to side anastomosis.

\section{Discussion}

Soft tissue defects of the lower extremity represent a challenging problem that requires a multidisciplinary approach involving both the reconstructive and orthopedic surgeons. The flap selection for lower extremity reconstruction is generally based on location of the defect, the size of the wound surface area, the type of deficient tissue components and their volume, status of the wound, the length of the pedicle, and the donor site and its morbidity. In terms of type of soft tissue flap, both fasciocutaneous and muscle flap are feasible options. Long bone defects most often need vascularised fibula flap for reconstruction.

In our study, all patients presented with soft tissue defects; hence we used ALT, LD and gracilis flaps. ALT flap was chosen most often since it offers the advantages of long, constant pedicle, two-team approach, large area of flap available depending on the defect and minimal donor site morbidity. LD flap was preferred for defects over weight-bearing heel \& sole while gracilis was chosen for small defects. According to the literature, survival and complication rates of fasciocutaneous ALT flaps and muscle flaps are comparable ${ }^{6,7,8,9,10,11,12}$. In our study, we found no significant difference between failure rates of muscle and fasciocutaneous flaps.

As far as vascular anastomosis is concerned, in most cases we performed an end-to-end arterial and venous anastomosis. However, in 4 cases where there was significant discrepancy between recipient \& donor arteries, an end-to-side anastomosis was performed. According to recent literature there is only a marginal difference in survival rates between end to end and end to side anastomoses ${ }^{13}$. We found no significant difference in flap failure or thrombosis rates between end to side and end to end anastomoses in our study. 


\section{Conclusion}

Free tissue transfer for reconstruction in patients with difficult wounds of the lower extremity is an excellent and effective procedure with a high success rate. Careful preoperative preparation and intraoperative attention to detail, combined with the use of microsurgical techniques are the keys for success.

Conflict of Interest: The authors have no conflict of interest to report

\section{References}

1. Engel, Holger, Lin, Chih-Hung, Wei, FuChan: Role of Microsurgery in Lower Extremity Reconstruction : J of Plastic and Reconstructive Surgery 2017 Jan; 127:228-238.

2. Kennith mattox; TRAUMA; seventh edition: 804.

3. Outcome Comparison between Free Muscle and Free Fasciocutaneous Flaps for Reconstruction of Distal Third and Ankle Traumatic Open Tibial FracturesYazar, Sukru; Lin, Chih-Hung; Lin, Yu-Te; More; Plastic and Reconstructive Surgery. 117(7):24682475, June 2006.

4. Reddy V, Stevenson TR. MOC-PS(SM) CME article: lower extremity reconstruction. Plast Reconstr Surg 2008;121(4, Suppl):1-7.

5. Evans K, Clemens M, Salgado C, Moran S, Mardini S. Fasciocutaneous versus muscle flap in soft tissue reconstruction. In: Pu LLQ, Levine JP, Wei F-C, eds. Reconstructive Surgery of the Lower Extremity, Part II. Chap. 22. St. Louis, USA: QMP; 2013:345-368.

6. Yildirim S, Gideroğlu K, Aköz $T$. Anterolateral thigh flap: ideal free flap choice for lower extremity soft-tissue reconstruction. J Reconstr Microsurg 2003;19(04):225-233.
7. Ozkan O, Coşkunfirat OK, Ozgentaş HE. The use of free anterolateral thigh flap for reconstructing soft tissue defects of the lower extremities. Ann Plast Surg 2004;53(05):455-461.

8. Yazar S, Lin CH, Lin YT, Ulusal AE, Wei FC. Outcome comparison between free muscle and free fasciocutaneous flaps for reconstruction of distal third and ankle traumatic open tibial fractures. Plast Reconstr Surg 2006;117(07):2468-2475, discussion 2476- 2477.

9. Paro J, Chiou G, Sen SK. Comparing muscle and fasciocutaneous free flaps in lower extremity reconstruction - does it matter? Ann Plast Surg 2016;76(03, Suppl 3): S213-S215.

10. Lin CH, Mardini S, Wei FC, Lin YT, Chen CT. Free flap reconstruction of foot and ankle defects in pediatric patients: longterm outcome in 91 cases. Plast Reconstr Surg 2006;117(07): 2478-2487.

11. Park JE, Rodriguez ED, Bluebond-Langer $\mathrm{R}$, et al. The anterolateral thigh flap is highly effective for reconstruction of complex lower extremity trauma. J Trauma 2007;62(01):162-165.

12. Wei FC, Jain V, Celik N, Chen HC, Chuang DC, Lin $\mathrm{CH}$. Have we found an ideal soft-tissue flap? An experience with 672 anterolateral thigh flaps. Plast Reconstr Surg 2002;109(07):2219-2226, discussion 2227-2230.

13. End-to-End versus End-to-Side Microvascular Anastomosis: A Metaanalysis of Free Flap Outcomes, J reconstr Microsurg 2017; 33(06): 402-411. 